Stress-strain relationships in yarns subjected to rapid impact loading. Part VIII: Shock waves, limiting breaking velocities, and critical velocities, J. C. Smith, J. M. Blandford, and K. M. Towne, Textile Research J. 32, No. 1. 67-76 (Jan. 1962).

The standards challenge, A. H. Scott, Insulation 8, No. 2, 48-50 (Feb. 1962).

Average decay laws for VLF fields, J. R. Wait, Proc. IRE 50, No. 1, 53-56 (Jan. 1962).

Radiation beam mapping with photographic film, W. L. MeLaughlin, Radiology 88, No. 1, 119-120 (Jan. 1962).
Current-limited rectifiers, G. F. Montgomery, Proc. IRE 50, No. 2, 190-193 (Feb. 1962).

* Publications for which a price is indicated (except for Technical Notes) are available only from the Superintendent of Documents, U.S. Government Printing Office, Washington 25, D.C. (foreign postage, one-fourth additional). Technical Notes are available only from the Office of Technical Service, IT.S. Department of Commerce, Washington 25, D.C. (order by $P B$ number). Reprints from outside journals and the NBS Journal of Research may often be obtained directly from the authors.

\title{
International Union of Geodesy and Geophysics to Meet in the United States
}

The XIII General Assembly of the International Union of Geodesy and Geophysics will be held at the University of California, Berkeley, 19-31 August 1963. The Union embraces the fields of geodesy, seismology, meteorology, geomagnetism, oceanography, volcanology, and hydrology. This will be the first meeting of the IUGG in the United States since 1939. With an estimated attendance of some 3000 scientists it is expected to be the largest international scientific meeting in the United States next year.

The two-week meeting will be preceded by a symposium at the University of California, Los Angeles, on the International Geophysical Year, and by a hydrology symposium at Stanford University. Following the General Assembly various technical field tours are being planned, and in addition a symposium on meterology will be held at Boulder, Colorado.

Copies of the First Circular describing the meeting are available upon request from Prof. David K. Todd, IUGG, University of California, Berkeley 4, California.

\section{ANNOUNCEMENT}

\section{Fundamental Change in the CRPL-D Series, Basic Radio Propagation Predictions}

A fundamental change in the form and content of the CRPL-D series, Basic Radio Propagation Predictions, will be made in January 1963. The first of the new form of predictions will be CRPL-D221, issued in January 1963, containing predictions for April 1963. Beginning with that issue, the predictions will be prepared by a method of numerical mapping using a high speed electronic computer. This method was developed by W. B. Jones and R. M. Gallet of CRPL. Instructions for use of the new predictions will be issued concurrently.

The new format will include tables of coefficients which, when used as input data with a suitable program, make possible the efficient use of a computer for calculation of detailed high frequency radio propagation predictions for any application.

World prediction maps for every even hour, Universal Time, will be provided for those who do not have the use of a computer. These will be actual world maps of zero-MUF and 4000-MUF, instead of the time charts for four zones appearing in previous issues. Methods for using the new maps will be similar to methods for using the former time charts. The D-series predictions will continue to be issued through the Superintendent of Documents, U.S. Government Printing Office, Washington 25, D.C. No change in subscription price is planned. 